\title{
Tackling Harm Reduction, Human Rights and Drug Uses on Recreational Environments: Tensions, Potentialities and Learnings from the Kosmicare Project (Portugal)
}

Redução de riscos, direitos humanos e usos de drogas em contextos de lazer: tensões, potencialidades e aprendizagens a partir do Kosmicare Project (Portugal)

Réduction de risques, droits humains et usages de drogues dans des contextes récréatifs: tensions, potentialités et apprentissages à travers le Kosmicare Project (Portugal)

Mónica Soares, Maria Carmo Carvalho, Mónica Valbom and Tânia Rodrigues

\section{OpenEdition}

\section{Journals}

Electronic version

URL: http://journals.openedition.org/rccs/6535

DOI: $10.4000 /$ rccs. 6535

ISSN: 2182-7435

Publisher

Centro de Estudos Sociais da Universidade de Coimbra

Printed version

Date of publication: 1 May 2017

Number of pages: 3-24

ISSN: 0254-1106

Electronic reference

Mónica Soares, Maria Carmo Carvalho, Mónica Valbom and Tânia Rodrigues, « Tackling Harm Reduction, Human Rights and Drug Uses on Recreational Environments: Tensions, Potentialities and Learnings from the Kosmicare Project (Portugal)», Revista Crítica de Ciências Sociais [Online], 112 | 2017, Online since 15 May 2017, connection on 19 April 2019. URL : http:// journals.openedition.org/rccs/6535; DOI : 10.4000/rccs.6535 


\section{MÓNICA SOARES, MARIA CARMO CARVALHO, MÓNICA VALBOM, TÂNIA RODRIGUES}

\section{Tackling Harm Reduction, Human Rights and Drug Uses on Recreational Environments: Tensions, Potentialities and Learnings from the Kosmicare Project (Portugal)}

This paper is organized into four parts of discussion. Firstly, we present the Portuguese decriminalization law and the central role of harm reduction within this framework. The second section discusses the mainstream meanings ascribed to the 'HR double' mainly anchored in problematic drug uses. The third section highlights the need to take into account the specificities of recreational drug uses, users and environments. Thus, the paper highlights the experience of the Kosmicare Project at the Boom Festival, which combines principles of harm reduction, crisis intervention and Grof's approach. The fourth section draws upon the project's experience itself and in the idea of the normalization of drug uses to acknowledge and to discuss the potentialities, tensions and limitations of these contributions when it comes to analyzing and constructing a strong version of the 'HR double'.

Keywords: decriminalization; drug policy; drug uses; harm reduction; human rights; recreational environments.

\section{Introduction: Seventeen Years of Drugs Decriminalization in Portugal}

Across the globe, the topic of drug uses has taken considerably different and controversial paths as multiple radicalizations and claims have been played out between the two main antagonistic legal foundations involved, that is, those who promote criminalization or those who favour legalization (Sommer, 2004). In Portugal in the early 1980s, changes occurred in the drug market in terms of supply with the introduction of heroin (Fernandes, 1997), the result of which was wide-spread disruptive patterns of use. It was as a result of this scenario that Decree-Law n. ${ }^{\circ} 430 / 83$ dated 13 December was conceived. Two major principles guided its implementation. First, drug trafficking was viewed as the epitome of delinquency and increasing 
criminality, thus requiring harsher punitive sanctions. Second, drug uses have become increasingly seen as a socially and legally punishable behaviour. In 1993, a new decree-law was published - Decree-Law n. ${ }^{\circ}$ 15/93, dated 22 January - which clearly prohibited drug trafficking and mandated concrete measures to control and monitor drug-related precursors (e.g., chemical products and solvents). The aim of this was to reduce the illicit production of any psychoactive substance (PAS) as much as possible.

Drug criminalization remained in place until 1999, largely due to the suspicion that any type of alternative policy would not utterly eradicate the drug problem. At this time, criminalization via the law was perceived as a sufficient deterrent, and decriminalization was too much of a fledgling idea to be fully adopted (Poiares, 2001). However, the repressive measures ended up showing different results. Heroin use was higher than ever, HIV/ /AIDS proliferation became a major public health concern, and the supply of new synthetic drugs and cocaine increased drastically (Quintas, 2011). In this context, however, drug use was decriminalized in Portugal in 1999 via resolution n. ${ }^{\circ} 46 / 99$, dated 26 May, afterward complemented with Decree-Law n. ${ }^{\circ} 30 / 2000$, dated 29 November. The decriminalization law inaugurated a period of tolerance towards the purchase, possession and use of drugs for personal intentions, as opposed to the production and sale of drugs, which is still criminalised in the present day (Greenwald, 2009). This legislative change transformed the illicit nature of drug use into an administrative transgression wherein courts were replaced by extrajudicial bodies - the Commissions for the Dissuasion of Drug Abuse (CDT) (Quintas, 2006). It must be noted, however, that decriminalization does not mean depenalization. Still, some foreseen consequences remain (e.g., fines, mandatory appearances before the CDT, etc.), which are applied to drug users who then are identified as administrative offenders. People who use drugs are also depicted as vulnerable persons (and not as criminals) possibly submitting themselves to treatment on a voluntary basis (Santos, 2004). Drug uses today is decriminalized, but its nature and users are still object of socio-legal censure (Fernandes, 2009).

A number of studies both in Portugal and internationally, have sought to address the law's impact up to the present. In 2006, a study analysed official and epidemiological evidence in order to understand the relationship between decriminalisation law and drug uses behaviour. Despite the increased attention the police paid to cannabis use and the rise in the number of drug users as persons of legal interest in general, the study also found a significant decrease in heroin and poly-drug uses and an increase in the treatment measures applied to problematic drug users (Quintas, 2006). 
This evolution in terms of the application of the law took place despite the concurrent tendency toward the moderate general increase in drug uses observed at the time. More recently, Gonçalves, Lourenço and Silva (2015) have studied the social cost of the Portuguese Drug Strategy approved in 1999, taking into consideration both health- and non-health-related costs. The study concluded that the social costs of drugs had decreased by $12 \%$ in the five years following the law's approval, and a significant $18 \%$ in the eleven-year period of its implementation. The study also concluded this reduction was observed not only in regard to the reduction of costs with the legal system, but also with health-related costs. Hughes and Stevens (2010) examined the Portuguese case contrasting the data regarding criminal justice and health impacts with other southern Europe countries such as Spain and Italy. They concluded that contrary to predictions, the Portuguese decriminalisation law did not result in major increases in drug use, with additional evidence in regard to reduction in problematic drug-use, drug-related harm and criminal justice overcrowding. Similar evidence regarding the number of drug users and the reduction of social problems was shown by Rosmarin and Eastwood (2012).

An additional consequence of the decriminalisation law was the implementation of harm reduction strategies fostered within its context. The Decree-Law n. ${ }^{\circ}$ 183/2001 dated 21 June consolidated the mission of harm reduction by shifting the pure legal interventionism toward a public health approach (Santos, 2004). By this time, harm reduction programmes were no longer a novelty in Portugal, but they existed at the margins operating in isolated and fragmented interventions promoted by institutions such as APDES (Agência Piaget para o Desenvolvimento) (Barbosa, 2009). But before introducing harm reduction practices in Portugal, some notes about the (un)defining features of this approach shall be made.

\section{The Harm Reduction Approach: Principles and Practices}

Thirty-six years after its emergence as a grassroots movement, the harm reduction approach is still interwoven in the paradox of being simultaneously promising and controversial (Collins et al., 2012). Interestingly, this dual nature has fostered the expansion of the harm reduction approach, leading to its incorporation into the mainstream visions of entities which deal with drug uses and health issues, including the US National Academy of Medicine, the American Medical Association, the European Union, and the World Health Organization, among others (cf. Collins et al., 2012; Drucker, 2013).

Indeed, the definition of harm reduction turns out to be much more complex when the multiplicity of practices which can be classified as 
falling under the harm reduction approach are recognised. Applied to drug uses, this approach tends to reflect a set of programmes sharing principles and practices in which the behaviours of drug users and their surrounding conditions are modified inasmuch as they prevent the serious risks that drugs pose to both the subject's and others' health and safety (MacCoun, 1998). Harm reduction began by recognising that individuals use drugs despite restrictive measures, and that drug uses can put users and their communities into high-risk situations if the related interventions are not guided by compassion, empathy and understanding (Marlatt and Tatarsky, 2010). Examples of harm reduction strategies include needle and syringe exchange, distribution of paraphernalia, low-threshold methadone maintenance, purpose-built injection facilities (i.e., micro-harm reduction strategies), safe-use educational campaigns, and treatment as an alternative to incarceration (i.e., macro-harm reduction strategies) (MacCoun, 1998; Rhodes et al., 2006).

In Portugal, the introduction of harm reduction programmes has had to undergo a lengthy process of earning recognition. The consolidation of harm reduction practices has been repeatedly delayed because of the political suspicion concerning harm reduction's efficiency in public health control (Barbosa, 2009). From 2000 onwards, the development of safe drug consumption facilities, educational campaigns in recreational settings and low-threshold methadone maintenance have become more common ${ }^{1}$ (ibidem). In this regard, the limited empirical and evaluative evidence has shown how these interventions have helped to reduce risk behaviour, promoted the adoption of safe sex practices and have encouraged drug users to take steps toward therapeutic action (Andrade et al., 2007). Furthermore, the introduction of harm reduction strategies has nurtured positive effects for the minimization of social exclusion, as well as for the decrease in criminal offenses and the control of infectious diseases (Barbosa, 2009).

Key to this success was a wider recognition of the worth of harm reduction with regard to access to health care and to informed choice. Human rights discourses, on both the micro and macro levels of intervention, were thus frequently mobilised to assemble legitimacy to harm reduction policies and practices as the“[...] language of human rights provides a comfortable,

\footnotetext{
${ }^{1}$ In Portugal, the most significant strategy for harm reduction has been the syringe exchange programme. The kit played a major role in preventing HIV/AIDS infection. This was achieved thanks to the work of 'street teams' who provided the information needed for drug users to take informed decisions on treatment for addiction (e.g., methadone treatment). This work was carried out through mobile units that frequented hotspots (e.g., zones known for their high rate of drug use). In fact, the prevention of STDs was one of the greatest achievements of the drug decriminalization law (Quintas, 2011).
} 
verbal touchstone for harm reductionists" (Hunt, 2004: 235). However, 'weak versions' of the human rights discourse ${ }^{2}$ are often the opaque backdrop in which harm reduction's claims tend to emerge mainly slanted towards problematic drug use.

\section{Harm Reduction and Human Rights: The 'HR Double'}

In a recent online article, Damon Barrett (2016), director of the International Centre on Human Rights and Drug Policy emphasized the need for acknowledging how the ideological resistance to harm reduction interventions is a barrier to human rights (e.g., access to health care) and how this problem has often been discounted by the mainstream human rights discourse. By locating the problem in international law, typically portraying and normalizing drug control and law prohibition as major concerns (i.e., the politics of zero-tolerance governing the 'war on drugs'), human rights policies have been ignored and criminal punishments have been carried out as the more suitable response:

Billions of people, four-fifths of the world population, lack access to opiates for the relief of pain. These are people with cancer, late-stage AIDS, injuries from accidents and so on [...]. More importantly, and related, too many people today still don't understand the scale of the damage and why it continues to happen [...] It marks the institutionalisation of a racist and colonial lack of tolerance for difference, culture and expression that is anathema to human rights. (Barrett, 2016)

Overall, this intersectional debate about harm reduction and human rights - the 'HR double' - tends to be circumscribed to well-documented concerns with: a) the spread of HIV/AIDS (Cohen and Wolfe, 2008; Jürgens et al., 2010; Rhodes et al., 2006); b) the mass incarceration of drug users in countries like the United States (cf. Drucker, 2011; Wacquant. 1999); and c) the control and cleanliness of heroin users and other intravenous drug users (i.e., the suppression of 'shooting galleries') through methadone-treatment

\footnotetext{
${ }^{2}$ The distinction between 'weak' and 'strong' perspectives on the entanglement involving human rights and harm reduction - what we designate in this paper as the 'HR double' - was developed by Neil Hunt (2004). The author differentiates between the two versions of the 'HR double' by taking into account two main criteria: a) the continuum level of sovereignty over the body ascribed to the drug user; b) the prioritization of public health or the subject's own choice. Weak versions tend to reflect the underlying yet dominant assumption that individuals are entitled to proper treatment. It tends then to foster human rights claims based on a paternalistic and health-based perspective. In contrast, strong versions tend to prioritize one's right over the body and the right to use drugs in their claims. Clearly, this distinction is non-linear but mainly directed to organize and to instrumentalize the 'HR double' whether the goal is to address drug use labelled as problematic or as non-problematic.
} 
programs (Drucker, 2013) or through the creation of injecting safe-places (Rhodes et al., 2006). Also in terms of macro-level analysis, this debate is often lead by the criticism of international law's control strategies, which are typically focused on the prohibition and eradication of drug production, commercialization and use, and how these have failed to prevent problematic drug uses and health-related problems (Drucker, 2013). As an alternative to the recognized inability of this legal-guided approach to deal with drug users' health and social problems, harm reduction strategies are in alignment with a human rights discourse, that is, in the behalf of the human dignity of the 'legally unstoppable' and 'health-vulnerable' drug user (understood as a drug addict). As Cohen and Wolfe point out:

The link between harm reduction and human rights goes deeper than legal arguments in support of a particular set of health services. [...] Traditional drug policy makes the cessation of illegal activity its highest priority. Harm reduction focuses instead on reducing risk, acknowledging that those who cannot or will not stop using drugs are still capable of positive change to protect their health or that of their communities. Where traditional drug policy relies upon detention, forced treatment and stigmatization as a means of deterrence, harm reduction recognizes that engaging in illegal activities does not mean forfeiting claims to healthcare or other basic protections. (2008: S94)

In fact, the lobbying effort which stakeholders in recent decades have engaged in has evolved into a more systematic criticism and disapproving assessment on the widespread prohibition of drugs. A case in point is the last United Nations General Assembly Special Session (UNGASS) in April 2016, which was directed to discuss global drug policy reforms in the light of harm reduction approaches and human rights protection. ${ }^{3}$ To be sure, harm reduction and its compassionate stance - in opposition to the abstinence and eradication paradigm aimed at dealing with drug uses - is more compatible with the mission of providing medical and social services to drug users who frequently see their rights being violated. It precludes the stigma, hyper-criminalization and marginalization of the drug users by portraying them as 'vulnerable human beings' victimized by structural factors and deprived of basic social rights. Amongst the drug users living with HIV/AIDS, the obstacles raised to their access to harm reduction

\footnotetext{
${ }^{3}$ Despite high expectations raised around the opportunity of a major global shift in drug policy, the latest UNGASS Meeting ended up reaffirming all the existing and prohibitionist-oriented international instruments as the "cornerstone of the international drug control system" (UNGASS, 2016: 3).
} 
services, the discrimination to their access to anti-retroviral therapy, or the coercion experienced with respect to drug treatments are practices seen as the denial of human rights protection (Jürgens et al., 2010).

Notwithstanding the importance of these arguments and the important impact they are proven to have, the pervasive influence of this 'weak human rights' framework (cf. Hunt, 2004) in Portugal still continues to produce a series of constraints and difficulties. More ambitious harm reduction practices are shunned by the abstinence-lead concerns within social and political discourses (i.e., harm reduction practices are a second way for combating the 'drug plague'). ${ }^{4}$ Even the ones that are being implemented suffer from a lack of concrete evaluations and from a tremendous vulnerability to political and economic fluctuant interests (Barbosa, 2009).

In addition, this 'HR double' is not sensitive to other drugs, sets and settings. The harm reduction practices of the state regularly tend to depend on the drug's illicit nature, and in this case they are highly directed toward intervention when it comes to problematic drug uses, mainly heroin. Indeed, often the drug user's behaviour only appears when it becomes framed within law enforcement or treatment services, now guided by socio-legal conceptions of priority (Duff, 2004). Notably absent are other figures (e.g., the 'raver', the youth) and other environments known for drug uses (e.g., music festivals) that go beyond the 'sick and deprived' junkie and the streets as the main environment in which drugs are used. The usefulness of the human rights discourse in redefining the answers provided by drug control policies is used with surgical precision because it depends on the figure of the 'vulnerable person' and in what is understood as a public health concern. Therefore, it does not leave room to question and to problematize the interventions provided to other kinds of drug uses. This might explain why in Portugal recreational environments are portrayed as almost absent from adequate actions on harm reduction (Silva, 2005).

Moreover, the impact and the consequences of recreational drug uses should not be undermined. The European Monitoring Centre for Drugs and Drug Addictions (EMCDDA) (cf. Fletcher et al., 2011) has recently documented the remarkable impact and risk (both physical and mental) associated with occasional or recreational drug uses, mainly among the

\footnotetext{
${ }^{4}$ Although the harm reduction approach is constructed in opposition to abstinence-driven interventions, some of the so-called 'harm-reduction style-practices' can still be overlapped in order to diminish the supply of drugs and to foster abstinence. In other words, at the same time they can be understood as harm protectors in the short-term, they also strive to promote a more effective long-term modification driven by abstinence with respect to the subject's behaviour. In this sense, although making some in-roads to public health, harm reduction programmes remain vulnerable to co-option, 'contradictory accommodations' or negation (Hathaway, 2002).
} 
youth population. Other indirect effects should also be noted such as accidental injuries, self-inflicted injuries, risk of suicide, unsafe sex practices, or risky driving. Within this text, it is still recognized that the broader spectrum of health promotion interventions registered since the 1980s needs to align with concrete strategies working with respect to mitigating social and environmental damage.

But how is this social and environmental damage understood in terms of risk? How can their modification account for risk reduction (and to benefit maximization too) within recreational environments? Why is harm reduction intervention in recreational environments typically ignored or fragmented? And, when it is applied, why is it typically accompanied by an attitude of the 'best management possible' taken by permissive environments or settings? To address these questions, it is necessary to take a closer look into the particularities of drug uses and recreational environments.

\section{Recreational Environments, the Kosmicare Project and the Boom Festival: Another piece for the puzzle of the 'HR double'}

Music and dance are today - as they have been since the beginning of humanity - key-elements of a certain type of leisure and pleasure time, encompassing the very diverse configurations and evolutions that culture has moulded over centuries. Undeniably, few phenomena surpass nightlife as a better metaphor for the relationship between freedom, the 'irresponsible experience', pleasure, the formation of identity and the dramatization of the 'disposable', undetermined and disengaged roles. Nightlife and recreational environments can be seen as the 'missing link' that combines our human need for pleasure with our processes of transition from youth to adulthood, as well as to those of our ancestors; one that unites our expressions of leisure with the influence of capitalism in advanced societies and also to the 'proto-leisure' in which the first human communities were already engaged. Within recreational environments, the norms and rules of adulthood are supplanted by the power of 'youthful emotions' freely expressed under the influence of music, dance, sexuality, alcohol, drug uses, and visual stimulation (Northcote, 2006). The rave experience seems to be as old as tribalism and the first communitarian human experiences (Hutson, 1999).

The recreational experience, the nightlife and all the enclosed phenomena are, regardless of their configurations (e.g., the electronic music festival; the rave culture; the supply of large urban night clubs; the most mainstream or the more alternative summer festivals), a global phenomenon. Something stable happens within these settings - "the culture of ecstasy and acid house movement work according to an inclusive logic. There is no dominant 
ideology - there are unlimited possibilities in which one can adapt himself in order to define his own identity, background, social status, and belief system" (Collin, 1997: 8). Hannerz (1986) explains why at present it is possible to develop a 'global culture', a non-homogenous repetition representing an interconnection of cultural locations and a non-rooted sense of inclusion.

The intentional modification of the consciousness (or of the mind) through drug uses is one of the most debated topics within this proliferation of recreational and nightlife experience context (Collin, 1997; Shiner and Newburn, 1999; Shapiro, 1999). Associated to this, drug uses are intensively connected with psychedelic music styles, such as techno and trance. Techno music is related to a profound disturbance of social order (Grynszpan, 1999) which

witnesses the emergence of new recreational facilities, a new way of making the party - the rave - revealing how the association between a music genre and a manifestation of leisure is constant, equally in trance music one of the most recent expressions of this relation. (Carvalho, 2007: 134)

As each music genre becomes differentiated from its original styles, the rupture requires the search for suitable locations for encountering the environmental features needed for its fullest expression. Moreover, drugs are chosen in accordance with their ability to amplify the lived experience of the places and of the aforementioned music genres. The drug user is not motivated by addiction; rather, it appears to be motivated by pleasure (Fletcher et al., 2011). Within recreational settings, drug users - mainly young adults - are raving in cultural spaces where drug uses are normalized. Thus drug uses arise as a common practice in which the users claim to be aware of the risks but they choose to use drugs nevertheless (Cruz and Machado, 2010). In many cases, these partygoers also claim to know how to manage their own risky behaviours whilst searching for new experiences and sensations (Moore et al., 2011).

The project we are about to introduce is developed at the Boom Festival, an outdoor music festival which incorporates these reflections on the connection between music, drugs and recreational environments. Within the Boom Festival, trance music is perhaps the genre which most stands out for its features and associated subculture. The symbolic universe of trance music is characterized by a transcendent experience in which the use of hallucinatory PAS (e.g., LSD) predominates as users seek trance states, inner journeys and deep insights. To contribute to this experience, 
psychedelic and fluorescent materials are used in event decorations, often with references to Hindu religious symbols, thereby contributing to sensorial stimulation and to the psychedelic experience (Carvalho, 2007; Chaves, 1998; Greener and Hollands, 2006). Hence, the Boom Festival is developed within this music climate in which drugs are tools to construct new meanings of experiencing the self and the surrounding world (Calado, 2006; Carvalho, 2007).

\section{A Harm Reduction Intervention in the Rave: The Kosmicare Project at the Boom Festival}

The expansion of nightlife and recreational environments has not been accompanied by a corresponding strong dissemination of information directed at recreational drug users on harm reduction interventions. An exception is the Boom Festival, a Portuguese multidisciplinary independent mega festival associated with psychedelic culture. The Boom Festival is United Nations Music and Environment Stakeholder Initiative partner also having a long history of international awards given its promotion of sustainable development. The festival's promotors - Good Mood, Lda. offer partygoers (i.e., 'boomers') medical assistance, psychological crisis intervention (Kosmicare Project) and other harm reduction strategies that include PAS testing (provided by APDES).

Kosmicare is a harm reduction and health promotion festival area based on a research and intervention project in operation to deal specifically with crisis situations (Carvalho et al., 2014). The main goal of the Kosmicare Project ${ }^{5}$ is to provide safe-places for drug users who are experiencing negative consequences mainly related to their drug uses. These experiences are understood as moments of crisis because the drug use experience can unfold very differently in comparison to the users' expectations, this being due to PAS, individual or environment related-factors. The Kosmicare Team - made up of doctors, nurses, psychologists and other therapists - intends to facilitate these episodes, at the same time supporting the person and offering strategies to turn this negative drug experience into an opportunity for personal growth. According to Grof (2008) an inadequate resolution of an individual's drug crisis may result in more persistent physical and mental injury. Crisis intervention principles coupled with Grof's principles of

\footnotetext{
${ }^{5}$ Kosmicare is developed and managed by Good Mood, Lda. (festival organizers), SICAD - the General Directorate for Drugs and Other Dependencies - which is the Portuguese Governmental Agency in charge of drug regulations and intervention and a university (Catholic University of Portugal) to ensure the adequacy of the interventions implementation and their evaluation (Carvalho et al., 2014).
} 
intervention in situations of unsupervised use of psychedelics (ibidem) and harm reduction principles (Collins et al., 2012) are then brought together to prevent risks, to promote health and to facilitate the integration of negative drug experiences. This is achieved by coupling strategies like "knowing and trusting the source of the substance, controlling set and setting (e.g., psychological preparation and physical surroundings), having a 'sitter' who can be mindful of safety [...]" (Tupper, 2008: 301). In this sense, some of the strategies provided by Komicare's team in order to ensure safety and to facilitate drugs' experience are talk therapy, offering a resting space, sitting quietly or walking with the 'boomers', physical contacts and other complementary strategies (e.g., music therapy, massaging or homeopathy) (Carvalho et al., 2014).

Once both the set and setting related to critical events pertaining to recreational environments are usually slighted (Measham, 2004), harm reduction practices developed within these - like in Kosmicare - are essential to promoting safety and protection during unsupervised drug uses. Moreover, these practices offer new insights on the practical and academic discourses related to the 'HR double'. The Kosmicare Project is also about finding space in academic discourse on the interconnection of music, environment, leisure, dignity and drug uses. As a consequence, it embodies and represents a concrete alternative to drug control and to traditional practices of harm reduction. In addition, these interventions require a paradigmatic shift from the control of the body to the modification of the environments.

\section{And Again, What Have Human Rights Got to do with it?}

The importance of extending the wide recognition that human rights discourses transfers to harm reduction practices in recreational environments implies taking up a shocking and disturbing question, mainly amongst some conservative human rights advocators and in mainstream discourses (e.g., Cohen and Wolfe, 2008). Should we be entitled to the right to use drugs? One of the most well-known and provocative proposals was offered by Erik van Ree (1999), who proposed the introduction of the Article 31 to the Universal Declaration of Human Rights. Seeking to defy prohibitionist measures and to instrumentalize the liberal tenets which the human rights discourse is based on, the author illuminated this new right as the following: "everyone has the right to use psychotropic substances of one's own choice" (ibidem: 89). To van Ree, the right to use drugs illustrates the freedom to use PAS of one's choice, a counterweighing manifesto to condemn the restrictions held by prohibitionist, abstinence-lead and/or exclusively hygienist interventions. Accordingly, if human rights are taken as self-evident, if they express serious 
commitments of societies as a whole, if the non-preservation of freedom can jeopardize human dignity, then the creation of this new right would demand respect to an individual's decisions concerning drug uses.

Hereafter, what are the implications of admitting that one has the 'individual right' to use drugs? What kind of elements should be taken into account to understand the 'HR double' when the right over the body is afforded advantage over pure public health concerns or prohibitionist intents? How can academics, therapists and drug users themselves construct, benefit and still raise criticism about a strong version of the 'HR double'? What are the potentialities? And what are the tensions and challenges ahead? To conduct this further analysis four axes will be guiding us: a) the normalization and acceptance of drug uses, but not the complete acceptance of unsupervised risk; b) the combination of non-interference principles (i.e., respect to the user's autonomy) with places and philosophies deep-seated in communitarian and interdependent lifestyles (e.g., the Boom Festival is deeply rooted in the oneness concept); c) the 'vulnerable subject' is replaced by the 'autonomous subject'; $d$ ) and the 'in-between' of drug harm, costs, pleasures and benefits. Each one of these four axes of analysis are supported in the concrete experience of the Kosmicare Project as they express current ideas, challenges and complexities of a strong version on the 'HR double' when a critical outlook on recreational drug uses in westernized contemporary societies is taken into account.

In the first place, within recreational spaces like the Boom Festival, it is possible to find a progressive cultural accommodation of 'no longer deviant' drug uses, turning it into a socially normative conduct (Parker et al., 1999; Parker, 2005). Critics of harm reduction have intensively contested the plausibility and strength of the amoral and non-judgemental philosophical tenets which harm reduction is based on because it can be counterproductive to the aim of attaining a more normalized vision of drug uses - i.e., if drugs are value-free, neither 'good' or 'bad', how can they be normalized? (Ezard, 2001; Keane, 2003; Hathaway, 2002). Furthermore, according to Keane (2003), one of the biggest paradoxes of harm reduction lies in the impossibility to practice a non-judgemental assessment of drugs and risk.

Following the Kosmicare experience, we can admit that the normalization of drug uses (as described above) is not incompatible with risk evaluation. However, in most of the cases, risk is evaluated by the drug user and not simply by an external expert. For example, when a partygoer is experiencing a deeply bad trip, the negative effects can be interrupted if some prescription drugs are administered. This process is only initiated if the drug user 
requests it, and/or when that crisis implies risks for the user's or another's safety. The standard intervention carried out is thus minimalistic and user-guided. The strategies implemented are more directed to protection via the place's redefinition (e.g., supply of water and food; organization of places to rest) than by the intervention in the body. But this 'stronger-version' of the 'HR double' is frequently criticised by the possibility of promoting harm due the normalization of manifold risks (cf. Hunt, 2004). In our view, an intermediate position is needed to evaluate risk. Clearly, in cases in which the partygoer is not able to make decisions, staff can intervene based on risk assessment. In the last instance, this process will never be value-free (e.g., the risk of endangering the subject's own life or another's life are conditions carefully evaluated by the medical team within Kosmicare), but it can respect the subject's choices.

Considering the above reflections, harm reduction interventions lead by the Kosmicare Project display a strong articulation between non-interference (i.e., the 'autonomous subject') and mutual support (i.e., the festival's communitarian environment). Confronting this issue, Andrew Hathaway (2002) has contested the pragmatic scope of harm reduction as a threat to human rights discourse founded on negative liberty values and non-interference. But harm reduction, as understood by some of its critics, is mostly related to public health-driven harm reductionism (Hunt, 2004) rather than to the whole set of practices enthused by harm reduction approach namely in recreational environments. The Kosmicare Project is not established in the 'junkie' figure, neither does it proclaim hygienist interventions. Having a right to take drugs may supersede health and humanist considerations without denying them. It respects and supports the individual drug user's decisions; at the same time it does not fall into rational choice extremisms.

At this point, a critical analysis of the 'rational drug user' is also important. Taking the Kosmicare Project experience into account, a more or less informed drug user does not mean the individual is less uncontrolled and unaware of the risks and injuries. The 'full rational and responsible' drug user is an impossible and counterproductive metaphor. Drug uses and their desired effects cannot be about a complete 'rational' discourse based on an individual cost-benefit analysis. Inside recreational environments, individual discourses on drug uses are carved out by sensation-seeking, and they are inexorably intersected by notions and expectations of pleasure, discovery, uncertainty and damage. These constructions are subjective, fixed on a sense of experience, a set of corporal and psychological experiences rooted in the body, also gaining meaning by contextual and cultural frameworks (Duff, 2008). 
Drug uses and the related-experiences are thus dynamic rather than static, understood as learning processes and, as such, drug users cannot be labelled as either fully responsible or as irresponsible agents. They can "naturally" choose to use different drugs and to adopt different control mechanisms (e.g., the frequency of use, the contexts of use, the combination with other drugs, temporary abstinence) (Grund et al., s/d) but drug use is an ever-changing process informed by concrete situations and by each situation-evolution. The Kosmicare team is confronted with different levels of subjective control. To recognize a 'right to take drugs' - while comprising the figure of an 'autonomous subject' - does not imply the creation of a rational drug user, but it emphasizes his/her freedom to make decisions over his/her own body, to control its effects, and similarly highlights the importance of providing non-restrictive support when subjective control is threatened.

Finally, another important point of discussion to allow for a deeper understanding of the 'HR double' lays in overemphasizing risks, which minimizes the pleasurable and positive effects related to drug uses (Duff, 2004, 2008; Holt and Treloar, 2008; White et al., 2006). By relying on Foucault's work on the 'practices of the self', Duff (2004) has discussed the use of drugs as 'arts of existence' oriented to transform and to change one's experience of life, to approach a different self, that is " $[\ldots]$ the means by which individuals come to establish for themselves a distinctive individual identity or subjectivity." (ibidem: 389). Mainly due to the festival's emphasis on creating an opportunity for personal growth through alternative lifestyles, drugs can be interpreted by 'boomers' as another possible 'gateway' to self-development and to the connection between boomers and nature, the community and others. Among partygoers, drug uses are not only stressed by their risks, but by their benefits.

The Kosmicare Project does not necessarily understand drug uses only as risk-producers. This legacy emerges from crisis intervention and from the principles of unsupervised use of psychedelics. The negative experience can be transformed into a positive one, which requires a shift to a more generative metaphor of drugs as 'tools' and benefit maximization as a reasonable aim (Tupper, 2008). This new metaphor acknowledges drugs as parts of a constructive set - i.e., what drugs allow to feel and to perform and setting in which the engagement with wilderness and life-affirming environments is usually cherished (Duff, 2008). Benefits can be multiple, comprising experiences of self-actualization (i.e., new insights about life events or crisis) or the overcoming of difficult experiences and traumas (cf. Rodrigues, 2013). Stating the 'right to have drugs' could mean to realize 
- and to overcome the insistence of a harm reduction approach to risks that drug uses have both risks as well as positive and pleasurable effects. Roughly speaking, we can admit that drugs can be equally 'good' and 'bad', and that this appraisal is not related to the legal or illegal conception of those drugs.

Worldwide drug policies share the intent to foster abstinence in terms of certain drugs labelled as illicit or unsafe; others should be used in moderation (e.g., alcohol in Western societies) (cf. Duff, 2004); and others are avowed as medicines, not necessarily due to their properties, but largely by means of medical recognition (cf. Tupper, 2008). Some of these recognized medicines are seen as dangerous if used outside the therapeutic realm that is within recreational ends (e.g., marijuana; ethnobotanics like iboga and ayahuasca). However, pleasure is never a debated issue because it transcends formal control in a large extent. In general social and academic discourses, drug uses with a recreational end are frivolous and spurious.

Here, the 'HR double' faces a great challenge: whether recreational drug uses constitute an important feature of human dignity, not only in the risks it can carries, but for the benefits it can bring to human development. The establishment of this overarching perspective in regard to drug uses in contemporary Western societies - representing the complex interplay of harm, cost, pleasures and benefits - demands the re-examination of the meanings and restrictions implied in drug uses and in supportive interventions. It also requires a broader redefinition of the conception of drugs, a more far-reaching normalization (and perhaps legalization) aimed at invigorating the safer access to drugs.

\section{Conclusion}

The harm caused and the pleasures derived from recreational drug uses are far from being seen as a vital piece within the 'HR double' puzzle. The pleasure may be seen as too irrelevant, unscientific and moot when comparing with the urgent and visible human sufferings (Conevey and Bunton, 2003; Duff, 2008). This work aimed to find a critical space to debate the counterproductive effects of not 'listening carefully' to recreational drug uses, both to the risks and to benefits ascribed to them. We started by advancing a brief history of decriminalization in Portuguese law and the central role of harm reduction in it. Next, we tackled the convergences and dissonances of the 'HR double' questioning its relevance and reformulation in the light of the progressive normalisation of drugs, non-problematic drug uses and recreational environments. To conduct this analysis, we relied upon the experience of the Kosmicare Project developed at the Boom Festival, a Portuguese 
biannual psychedelic music festival. By taking an environmental focus in the creation of safe-places, the Kosmicare Project has provided some insights as a consolidated intervention able to reposition the interplay of the 'HR double'.

Far from being completely addressed, this work has represented an effort to discuss the possibilities of expansion and critical development that recreational drug uses can inform in regard to the mainstream discourses connecting harm reduction and human rights. Our reflections point out the relevance of building more inclusive, critical and stronger versions on the 'HR double' capable of recognizing the complex and relevant entanglements between risk and pleasure, cost and benefit, autonomy and support, and freedom and intervention in recreational settings. We have come close to the idea that in less or more 'responsible' drug user, the subject's own choice must be respected and maximized as much as possible. Interventions should be supportive and mainly oriented to the spaces' redefinition. Risk assessment should not be overlooked, but benefits should not be left outside the puzzle either. Both on national and international levels, surely these reflections will offer important contributions in debates about macro-policies, in which the discussion of the potentialities and limits of drug legalization are main topics to address in the future.

\section{Edited by Scott M. Culp}

\section{References}

Andrade, Paula; Carapinha, Ludmila; Sampaio, Miguel; Shirley, Susana; Rodrigues, Isabel; Silva, Marta (2007), "Para além do espelho: a intervenção de proximidade nas toxicodependências", Toxicodependências, 13(2), 9-24.

Barrett, Damon (2016), Guest Editorial - Some Thoughts on Human Rights and the War on Drugs. Accessed on 29.02.2016, at http://www.drugfoundation.org.nz/ matters-of-substance/february-2016/human-rights-war-drugs.

Barbosa, Jorge (2009), "A emergência da redução de danos em Portugal: da 'clandestinidade’ à legitimação política”, Toxicodependências, 15(1), 33-42.

Calado, Vasco (2006), Drogas sintéticas - Mundos culturais, música trance e ciberespaço. Lisboa: IDT.

Carvalho, Maria Carmo (2007), Culturas juvenis e novos usos de drogas em meio festivo. Porto: Campos das Letras.

Carvalho, Maria Carmo; Pinto de Sousa, Mariana; Frango, Paula; Dias, Pedro; Carvalho, Joana; Rodrigues, Marta; Rodrigues, Tânia (2014), "Crisis Intervention Related to the Use of Psychoactive Substances in Recreational Settings - Evaluating the Kosmicare Project at Boom Festival”, Current Drug Abuse Reviews, 7, 81-100. 
Chaves, Miguel (1998), “Consumos de 'novas drogas': pontos de partida para a investigação sociológica”, Toxicodependências, 2, 15-23.

Cohen, Jonathan; Daniel; Wolfe (2008), "Harm Reduction and Human Rights: Finding common cause”, AIDS, 22(suppl. 2), S93-S94.

Collin, Matthew (1997), Altered State - The Story of Ecstasy Culture and Acid House. London: Serpent Tail.

Collins, Susan; Clifasefi, Seema; Logan, Diane; Samples, Laura; Somers, Julian; Marlatt, Alan (2012), "Current Status, Historical Highlights, and Basic Principles of Harm Reduction”, in Alan Marlatt, Mary Larimer, Katie Witkiewitz (eds.), Harm Reduction: Pragmatic Strategies for Managing High-Risk Behaviors. New York: The Guilford Press, 3-35 [2nd ed. $]$.

Coveney, John; Bunton, Robin (2003), "In Pursuit of the Study of Pleasure: Implications for health research and practice", Health: An Interdisciplinary Journal for the Social Study of Health, Illness and Medicine, 7(2), 161-179.

Cruz, Olga; Machado, Carla (2010), “Consumo ‘não problemático’ de drogas ilegais”, Toxicodependências, 16(2), 39-47.

Decree-Law no. 430/83 of 13 December. Diário da República n. ${ }^{\circ} 285$ - I Série A. Lisboa: Ministério da Justiça e Ministério da Saúde.

Decree-Law no. 15/93 of 22 January. Diário da República n. ${ }^{\circ} 18$ - I Série. Lisboa: Ministério da Justiça.

Decree-Law no. 30/00 of 29 November. Diário da República n. ${ }^{\circ} 276$ - I Série A. Lisboa: Ministério da Justiça.

Decree-Law no. 183/2001 of 21 June. Diário da República n. ${ }^{\circ} 140$ - I Série A. Lisboa: Ministério da Administração Interna.

Drucker, Ernest (2011), A Plague of Prisons: The Epidemiology of Mass Incarceration in America. New York: The New Press.

Drucker, Ernest (2013), “Advocacy Research in Harm Reduction Drug Policies”, Journal of Social Issues, 69(4), 684-693.

Duff, Cameron (2004), "Drug Use as a 'Practice of the Self': Is There Any Place for an 'Ethics of Moderation' in Contemporary Drug Policy?”, International Journal of Drug Policy, 15, 385-393.

Duff, Cameron (2008), “The Pleasure in Context”, International Journal of Drug Policy, 19, 384-392.

Ezard, Nadine (2001), "Public Health, Human Rights and the Harm Reduction Paradigm: From Risk Reduction to Vulnerability Reduction”, International Journal of Drug Policy, 12, 207-219.

Fernandes, Luís (1997), Atores e territórios psicotrópicos: etnografia das drogas numa periferia urbana. Tese de doutoramento apresentada à Universidade do Porto, Faculdade de Psicologia e Ciências da Educação, Porto, Portugal. 
Fernandes, Luís (2009), “O que a droga faz à norma”, Toxicodependências, 15(1), 3-18. Fletcher, Adam; Calafat, Amador; Pirona, Alessandro; Olzewski, Deborah (2011), "Young People, Recreational Drug Use and Harm Reduction", Addiction, 106, 37-46. DOI: 10.1111/j.1360-0443.2010.03316.

Gonçalves, Ricardo; Lourenço, Ana; Silva, Sofia Nogueira da (2015), “A Social Cost Perspective in the Wake of the Portuguese Strategy for the Fight against Drugs", International Journal of Drug Policy, 26, 199-209.

Greener, Tracey; Hollands, Robert (2006), "Beyond Subculture and Post-subculture? The Case of Virtual Psytrance", Journal of Youth Studies, 9(4), 393-418.

Greenwald, Glenn (2009), Drug Decriminalization in Portugal. Lessons for Creating Fair and Successful Drug Policies. Washington D.C.: Cato Institute.

Grof, Stanislav (2008), LSD Psychotherapy. California: MAPS.

Grund, Jean Paul; Ronconi, Susanna; Zuffa, Grazia (s/d), "Beyond the Disease Model, New Perspectives in HR: Towards a Self-regulation and Control Model”. Accessed on 01.03.2016, at http://www.academia.edu/8377272/Beyond_the_disease_model_new_ perspectives_in_HR_towards_a_self_regulation_and_control_model_Operating Guidelines_by_Jean_Paul_Grund_Susanna_Ronconi_Grazia_Zuffa.

Grynszpan, Emmanuel (1999), Bruyante techno - Réflexion sur le son de la free-party. Nantes: Éditions Seteun.

Hannerz, Ulf (1986), Exploración de la ciudad. Madrid: Fondo de Cultura Económica. Hathaway, Andrew (2002), "From Harm Reduction to Human Rights: Bringing Liberalism Back into Drug Reform Debates”, Drug and Alcobol Review, 21, 397-404.

Holt, Martin; Treloar, Carla (2008), "Pleasure and Drugs", International Journal of Drug Policy, 19, 349-352.

Hughes, Caitlin Elizabeth; Stevens, Alex (2010), "What can we Learn from the Portuguese Decriminalization of Illicit Drugs?”, British Journal of Criminology, 50, 999-1022.

Hutson, Scott (1999), “Technoshamanism: Spiritual Healing in the Rave Subculture”, Popular Music and Society, 23(1), 53-77.

Hunt, Neil (2004), "Public Health or Human Rights: What Comes First?”, International Journal of Drug Policy, 15, 231-237.

Jürgens, Ralf; Csete, Joanne; Amon, Joseph; Baral, Stefan; Beyrer, Chris (2010), "People Who use Drugs, HIV, and Human Rights", The Lancet, 376(7), 475-485.

Keane, Helen (2003), "Critiques of Harm Reduction, Morality and the Promise of Human Rights”, International Journal of Drug Policy, 14, 227-232.

MacCoun, Robert (1998), “Toward a Psychology of Harm Reduction”, American Psychologist, 53(11), 1199-1208.

Marlatt, Allan; Tatarsky, Andrew (2010), "State of the Art in Harm Reduction Psychotherapy: An Emerging Treatment for Substance”, Journal of Clinical Psychology, 66(2), 117-122. 
Measham, Fiona (2004), "Play Space: Historical and Socio-cultural Reflections on Drugs, Licensed Leisure Locations, Commercialization and Control”, International Journal of Drug Policy, 15, 337-345.

Moore, Karenza; Measham, Fiona; Østergaard, Jeanette; Fitzpatrick, Claire; Bhardwa, Bina (2011), Emerging Drug Trends in Lancashire: Focusing on young adults' alcohol and drug use. Phase Two Report. Lancashire: Lancashire Drug and Alcohol Action Team.

Northcote, Jeremy (2006), "Nightclubbing and the Search for Identity: Making the Transition from Childhood to Adulthood in an Urban Milieu", Journal of Youth Studies, 9(1), 1-16.

Quintas, Jorge (2006), Regulação legal do consumo de drogas: impactos da experiência portuguesa da descriminalização. Tese de doutoramento. Porto: Universidade do Porto, Faculdade de Direito - Escola de Criminologia.

Quintas, Jorge (2011), Regulação legal do consumo de drogas: impactos da experiência portuguesa da descriminalização. Porto: Fronteira do Caos Editores.

Parker, Howard (2005), "Normalization as a Barometer: Recreational Drug Use and the Consumption of Leisure by Younger Britons", Addiction Research and Theory, 13, 205-215. DOI: 10.1080/16066350500053703.

Parker, Howard; Aldrigde, Judith; Measham, Fiona (1999), Illegal Leisure - The Normalization of Adolescent Recreation Drug Use. London: Routledge.

Poiares, Carlos (2001), "Variações sobre a droga", Revista Toxicodependências, 7(2), 67-75.

Rhodes, Tim; Kimber, Jo; Small, Will; Fitzgerald, John; Kerr, Thomas; Hickman, Matthew; Holloway, Greg (2006), "Public Injecting and the Need for 'Safer Environment Interventions' in the Reduction of Drug-Related Harm”, Addiction, 101, 1384-1393.

Rodrigues, Tânia (2013), “Avaliação dos resultados de um programa de intervenção em crise nos usos de SPA em ambientes recreativos: Follow-up dos participantes do programa Kosmicare”. Dissertação de mestrado apresentada à Universidade Católica Portuguesa, Porto, Portugal.

Rosmarin, Ari; Eastwood, Niamh (2012), A Quiet Revolution: Drug Decriminalisation Polices in Practice Across The Globe. Release Publication.

Santos, Maria (2004), "Contributos para uma análise da experiência descriminalizadora do consumo de drogas”, Toxicodependências, 10(1), 37-42.

Shapiro, Harry (1999), "Dances with Drugs: Pop Music, Drugs and Youth Culture”, in Nigel South (ed.), Cultures, Controls E Everyday Life. London: SAGE, 17-35.

Shiner, Michael; Newburn, Tim (1999), "Taking Tea with Noel: The Place and Meaning of Drug Use in Everyday Life”, in Nigel South (ed.), Drugs: Cultures, Controls and Everyday Life. London: SAGE, 140-159.

Silva, Vitor (2005), “Techno, house e trance. Uma incursão pelas culturas da 'Dance Music”, Toxicodependências, 1(3), 63-73. 
Sommer, Manuel (2004), Carreira de saída da toxicodependência. Lisboa: Climepsi Editores.

Tupper, Kenneth (2008), “The Globalization of Ayahuasca: Harm Reduction or Benefit Maximization?”, International Journal of Drug Policy, 19, 297-303.

UNGASS, United Nations Office on Drugs and Crime (2016), Our Joint Commitment to Effectively Addressing and Countering the World Drug Problem. Draft Resolution (A/S-30/L.1). United Nations: Office on Drugs and Crime.

van Ree, Erik (1999), "Drugs as a Human Right”, International Journal of Drug Policy, 1, 89-98.

Wacquant, Loïc (1999), As prisões da miséria. Lisboa: Celta.

White, Bethany; Degenhardt, Louisa; Breen, Courtney; Bruno, Raimondo; Newman, Jaclyn; Proudfoot, Phoebe (2006), "Risk and Benefit Perceptions of Party Drug Use", Addictive Behaviours, 31, 137-142.

Received on 23.03.2016

Accepted for publication on 16.01.2017

\section{Mónica Soares}

Centro de Estudos Sociais da Universidade de Coimbra

Colégio de São Jerónimo, Largo Dom Dinis, Apartado 3087, 3000-995 Coimbra, Portugal

Contact: monicasoares@ces.uc.pt

\section{Maria Carmo Carvalho}

CEDH - Centro de Estudos em Desenvolvimento Humano, Faculdade de Educação e Psicologia, Universidade Católica Portuguesa

Rua de Diogo Botelho, n. ${ }^{\circ}$ 1327, 4169-005 Porto, Portugal

Contact: mccarvalho@porto.ucp.pt

\section{Mónica Valbom}

Faculdade de Educação e Psicologia, Universidade Católica Portuguesa Rua de Diogo Botelho, n. ${ }^{\circ}$ 1327, 4169-005 Porto, Portugal

Contact: monicavalbom@hotmail.com

\section{Tânia Rodrigues}

Faculdade de Educação e Psicologia, Universidade Católica Portuguesa Rua de Diogo Botelho, n. ${ }^{\circ}$ 1327, 4169-005 Porto, Portugal

Contact: tania.neves.rodrigues@gmail.com 


\section{Redução de riscos, direitos humanos e usos de drogas em contextos de lazer: tensões, potencialidades e aprendizagens a partir do Kosmicare Project (Portugal)}

O presente texto está organizado em quatro secções de discussão. Em primeiro lugar, discute-se a lei portuguesa de descriminalização do uso de drogas e a sua função na abordagem da redução de riscos. A segunda parte discute os significados tipicamente atribuídos ao 'HR double', geralmente ancorados em usos de drogas problemáticos. A terceira parte enfatiza a necessidade de tomar em linha de conta as especificidades dos usos de drogas em contextos de lazer, seus consumidores e ambientes. Assim, este trabalho privilegia a experiência do Projeto Kosmicare no Boom Festival, que combina princípios de redução de riscos, de intervenção em crise e da abordagem de Grof. A quarta secção é desenvolvida a partir do projeto em si e da ideia de normalização de usos de drogas, de modo a reconhecer e a discutir as potencialidades, tensões e limitações destas contribuições quando se trata de analisar e construir uma versão forte do 'HR double'. Palavras-chave: descriminalização; direitos humanos; políticas de drogas; redução de riscos; usos de drogas; contextos de lazer.
Réduction de risques, droits humains et usages de drogues dans des contextes récréatifs: tensions, potentialités et apprentissages à travers le Kosmicare Project (Portugal)

Le présent article est organisé en quatre sections de discussion. La première présente la loi portugaise de décriminalisation d'usage de drogues et son rôle central de réduction des risques dans ce cadre. La deuxième examine le sens généralement attribué à "double HR", principalement ancré dans les usages de drogues problématiques. La troisième met l'accent sur la nécessité d'examiner les spécificités des drogues récréatives, ses utilisateurs et environnements. Ainsi, cet article se concentre sur l'expérience du "Kosmicare Project" au Boom Festival, qui combine les principes de réduction de risques, d'intervention de crises et de l'approche de Grof. La quatrième section s'appuie sur l'expérience du projet lui-même et sur l'idée de la normalisation de l'usage de drogues pour reconnaitre et discuter les potentialités, tensions et limitations de ces contributions en matière d'analyse et de construction d'une version forte de "double HR".

Mots-clés: décriminalisation; droits humains; environnements récréatifs; politiques des drogues; réduction des risques; usages de drogues. 
